\title{
Posicionamentos identitários e imagens de si na formação do profissional de Letras
}

\author{
Positional identity and images of themselves in the professional training of Letters
}

\author{
Renata Oliveira Marques Gomide \\ Pontifícia Universidade Católica de Minas Gerais - Belo Horizonte - Minas Gerais - Brasil
}

\begin{abstract}
$\diamond$
Resumo: Este trabalho investiga os posicionamentos discursivo-enunciativos de alunos em processo de formação acadêmico-profissional em Letras, a fim de compreender os movimentos de emergência identitária desses sujeitos na tessitura de seus textos. Tendo em vista não somente a organização da composicionalidade textual como também as condições de produção dos discursos, são analisados diferentes mecanismos enunciativos e discursivos (particularmente as estratégias de referência pessoal, as modalizações e o jogo de vozes) em atividades acadêmicas desenvolvidas por alunos em formação inicial ( $2^{\circ}$ período $)$, recém-ingressados na universidade, e por alunos no último ano do curso ( $7^{\circ}$ período), às vésperas de se formarem. Em vista disso, a análise do corpus contempla as diversas formas pelas quais o sujeito investe-se para dizer o que diz e como diz, com o objetivo de apreender as imagens que ele constrói sobre a própria formação, bem como os papéis sociais que assume e suas ações na esfera acadêmica.
\end{abstract}

Palavras-chave: Posicionamentos identitários; Jogo de vozes; Referência pessoal; modalizações

\begin{abstract}
This work investigates the discursive and enunciative positioning of students in process of formation in Modern Languages, in order to understand the emergence of identity movements of these subjects in their texts. Considering not only the organization of textual compositionality but also the conditions of discourse production, this work analyzes differents discursive and enunciative mechanisms (particularly the strategies of personal reference, modalizations and management of voices) in academic activities written for students in initial training (2nd period), recently admitted at the university, and students in the last year of the course (7th period). As a result, analysis attempts to address the various ways in which the subject invests up to what it says and as he says, aiming to capture the images he builds on his own training as well as the social roles that takes and their actions in the academic sphere.

Keywords: Positional identity; Management of voices; Personal reference; Modalizations
\end{abstract}

\section{Introdução}

Este artigo apresenta uma análise sobre os posicionamentos discursivo-enunciativos de alunos em processo de formação acadêmico-profissional em Letras, a fim de compreender os movimentos de constituição identitária desses sujeitos na tessitura de seus textos. Tendo em vista não somente a organização da composicionalidade textual como também as condições de produção dos discursos, são analisados diferentes mecanismos enunciativos e discursivos (particularmente as estratégias de referência pessoal, as modalizações e o jogo de vozes) em atividades acadêmicas desenvolvidas no âmbito das disciplinas que compõem os Núcleos de Interseção constituintes do Projeto Pedagógico do Curso de Letras da PUC Minas implementado a partir de 2006. Buscando-se alcançar uma visão transversal do percurso de formação dos sujeitos pesquisados, são analisadas produções textuais escritas de alunos em formação inicial ( $2^{\circ}$ período), recém-ingressados na universidade, e de alunos no último ano do Curso ( $7^{\circ}$ período), às vésperas de se formarem.

Em vista disso, a análise contempla as diversas formas pelas quais o sujeito investe-se para dizer o que diz e como diz, com o objetivo de apreender as imagens que ele constrói sobre a própria formação, bem como os papéis 
sociais que assume e suas ações na esfera acadêmica. Trata-se de uma investigação que leva em conta tanto o plano do enunciado, no que concerne aos processos de referência pessoal, modalizações e jogo de vozes, quanto o plano da enunciação, relativo à cena enunciativa, em que se refletem as injunções sócio-históricas do discurso. Em suma, considera-se que as marcas linguísticas presentes na materialidade dos textos constituem um espaço de sentido em que é possível analisar os modos pelos quais esses sujeitos constroem, agenciam e negociam discursiva e enunciativamente suas identidades no curso da atividade de linguagem em exame.

\section{Posicionamentos identitários e imagens de si: a emergência do sujeito no discurso}

Ao reconhecer que a linguagem é muito mais que um instrumento de comunicação, os estudos do campo da linguagem, em especial aqueles que enfatizam a relação de interface entre o social e o cognitivo, buscam compreendêla não apenas como um sistema formal de signos, mas também como uma atividade social, histórica, cultural, cognitiva e interacional. Dessa perspectiva, marcada por um viés transdisciplinar, admite-se que a linguagem produz discursos e que essa produção pressupõe a situação em que tais discursos são constituídos, o modo como são ditos e as condições de interlocução ${ }^{1}$. Ora, se é pela troca intersubjetiva, fundada pela linguagem, que se configuram as diversas atividades sociais de comunicação, e sendo o discurso - materializado numa dada língua natural - o próprio lugar da interação, então, deve-se tomar como importante o princípio segundo o qual o sujeito se constrói e é construído na (e pela) linguagem, de acordo com as atividades sociais de que participa ou integra. Diante disso, ressalte-se que um importante pressuposto deste trabalho é que a construção do indivíduo como sujeito social, histórico e cultural se dá em função das práticas de linguagem promovidas pelas (e nas) interações humanas.

Nesse quadro teórico-metodológico, concebendose, com Bakhtin/Volochínov (2004), que a linguagem é essencialmente dialógica, admite-se, por um lado, seu caráter social e, por outro, sua função reguladora da atividade linguística dos interlocutores na interação verbal. De fato, para Bakhtin/Volochínov (2004), a dimensão da subjetividade decorre das noções de dialogismo e ideologia, ambas constitutivas da linguagem. Não se trata de uma dimensão nem subjetivista, nem objetivista, mas marcadamente sociológica, formulada à luz do conflito ideológico. Desse ponto de vista, o centro organizador e

\footnotetext{
Ver Bronckart (2003, 2008); Gnerre (1988); Kleiman (1995); Orlandi (1985); Marcuschi (2003); Matencio (2001); Signorini (1998); Soares (2003).
}

formador da enunciação não se situa exclusivamente na interioridade do sujeito, mas na exterioridade da situação social em que a enunciação se realiza. $\mathrm{O}$ ato discursivo individual do sujeito passa a ser pensado em face da interação e, portanto, deixa de representar um movimento completo em si mesmo, pois o que o determina não é somente o sujeito que o realiza, mas os interlocutores aos quais se dirige. A constituição do sujeito é, assim, fundamentalmente intersubjetiva e social: o "eu" só se define em relação ao "outro".

Nesse sentido, a identidade implica uma relação de interface entre o social/cultural e o individual, sendo, por isso, um movimento de diferenciação do "eu" em relação ao "outro", mas também um movimento de inclusão do "eu" na coletividade. Nos dados coletados para análise, por exemplo, os sujeitos se colocam em diferentes campos sociais, assumindo uma postura individual de aluno e/ ou de professor/profissional em formação, mas também coletiva, ao falar em nome da turma.

Sob o viés dos Estudos Culturais, Hall (2000) salienta que a noção de identidade deve ser concebida à luz tanto dos discursos e práticas sociais de interação quanto dos processos subjetivos:

Utilizo o termo "identidade" para significar o ponto de encontro, o ponto de sutura, entre, por um lado, os discursos e práticas que tentam nos "interpelar", nos falar ou nos convocar para que assumamos nossos lugares como os sujeitos sociais de discursos particulares e, por outro lado, os processos que produzem subjetividades, que nos constroem como sujeitos aos quais se pode "falar". (HALL, 2000, p. 111-112)

Tal perspectiva insere-se em uma problemática mais ampla, segundo a qual, nas sociedades modernas, o sujeito torna-se cada vez mais fragmentado. Nesse cenário, as identidades são radicalmente instáveis e passam a ser vistas como um processo contínuo de mudança e transformação. Assim, assume-se aqui que o sujeito é, a um só tempo, social e singular. Sua identidade é construída, agenciada, negociada. Construída por meio das relações sociais que mantém com o "outro" e com os "outros eus" que o constituem enquanto sujeito. Agenciada discursivamente pelas posições enunciativas assumidas na interação (pelo próprio processo de autorreferenciação). E negociada em função da situação e dos lugares sociais de onde se fala.

Ressalte-se, pois, a plasticidade do posicionamento identitário do sujeito e suas diferentes manifestações nas interações sociais, uma vez que "embora possamos nos ver, seguindo o senso comum, como sendo a "mesma pessoa' em todos os nossos diferentes encontros e interações", conforme argumenta Woodward (2000, p. 30), "não é difícil perceber que somos diferentemente 
posicionados, em diferentes momentos e em diferentes lugares, de acordo com os diferentes papéis sociais que estamos exercendo".

Acentua-se, aqui, um ponto importante para esta investigação: os posicionamentos identitários não só dependem de papéis atribuídos socialmente, como também apresentam posições subjetivas. Ao fazer referência a "si mesmo" e ao "outro", o sujeito assume determinados posicionamentos identitários que marcam tanto sua individualidade quanto sua relação com o mundo exterior: "Enquanto eu falo evidencia-se a objetivação - pelo eu mesmo que fala - e manifesta-se, também, um movimento de subjetivação - ou seja, põem-se em evidência traços de intenção subjetiva do sujeito, sua singularidade" (SILVA; MATENCIO, 2005, p. 252, grifos das autoras).

Marcando a emergência do sujeito no discurso, a subjetivação constitui um processo pelo qual se constrói uma posição identitária e pelo qual o sujeito representase a partir de determinados lugares sociais, assumindo determinados papéis no curso da interação. A subjetivação assim construída por meio da linguagem, sendo uma ação fundamentalmente intrassubjetiva/autorreflexiva, remete à capacidade do ser humano de constituir-se como sujeito em relação ao "outro" e a si mesmo, o que concorre para a manifestação de uma posição identitária.

À luz do exposto até o momento, faz-se necessário apresentar o que se entende por "posicionamento" neste trabalho. Por implicar a ideia de instauração e conservação de uma identidade enunciativa, Maingueneau (2006, p. 392) afirma que tal conceito é uma categoria de base da Análise do Discurso e designa "ao mesmo tempo as operações pelas quais essa identidade enunciativa se instaura e se conserva num campo discursivo e essa própria identidade" (grifos do autor). O autor explica também que "o posicionamento não diz respeito apenas aos 'conteúdos', mas às diversas dimensões do discurso: ele se manifesta também na escolha destes ou daqueles gêneros de discurso, no modo de citar etc.". Além disso, "posicionamento", para o autor, configura não apenas "um conjunto de textos, um corpus, mas uma imbricação entre um modo de organização social e um modo de existência de textos" (MAINGUENEAU, 2008, p. 45).

Com efeito, a noção de posicionamento é estreitamente relacionada ao amplo e, muitas vezes, controverso conceito de "formação discursiva" (FD), afinal, pode-se dizer que a posição assumida pelo sujeito na interação é determinada pela formação discursiva de que faz parte: "aquilo que o sujeito diz se inscreve em uma formação discursiva e não outra para ter um sentido e não outro" (ORLANDI, 2007, p. 47).

Formulada por Foucault (2007) e retomada por diversos outros autores no âmbito dos estudos do discurso, a expressão "formação discursiva" é pensada em termos de "performances verbais" e forneceria uma espécie de parametrização de grupos de enunciados, sócio-historicamente determinados. Da mesma forma que a regularidade de uma frase é definida pelo sistema da língua, a regularidade dos enunciados poderia sê-lo em função de uma determinada formação discursiva:

Um enunciado pertence a uma formação discursiva, como uma frase pertence a um texto, e uma proposição a um conjunto dedutivo. Mas enquanto a regularidade de uma frase é definida pelas leis de uma língua, e a de uma proposição pelas leis de uma lógica, a regularidade dos enunciados é definida pela própria formação discursiva. (FOUCAULT, 2007, p. 132)

Sob esse aspecto, o sujeito, a partir de sua dispersão e descontinuidade, é visto como uma função. O elemento nuclear da formação discursiva, o enunciado, constitui um espaço vazio, no qual os sujeitos podem vir a assumir diferentes posições; o sujeito é, no caso, entendido como

[...] um lugar determinado e vazio que pode ser efetivamente ocupado por indivíduos diferentes. [...] Se uma proposição, uma frase, um conjunto de signos podem ser considerados "enunciados", não é porque houve, um dia, alguém para proferi-los ou para depositar, em algum lugar, seu traço provisório; mas sim na medida em que pode ser assinalada a posição do sujeito. Descrever uma formulação enquanto enunciado não consiste em analisar as relações entre o autor e o que ele disse (ou quis dizer, ou disse sem querer), mas em determinar qual é a posição que pode e deve ocupar todo indivíduo para ser seu sujeito. (FOUCAULT, 2007, p. 107-108)

Ao trazer a noção de formação discursiva para o centro da Análise do Discurso, Pêcheux (1988) funde esse princípio à filosofia marxista de Althusser (1983), na qual o sujeito, submisso às ideologias dominantes, é considerado, sobretudo, como um efeito de estruturas sociais. Dessa concepção resulta a ideia de que o discurso confere existência material à ideologia e constitui-se a partir de um conjunto de enunciados pertencentes a uma determinada formação discursiva, sendo esta sempre atravessada por formações ideológicas:

O sentido de uma palavra, de uma expressão, de uma proposição, etc., não existe "em si mesmo" (isto é, em sua relação transparente com a literalidade do significante), mas, ao contrário, é determinado pelas posições ideológicas que estão em jogo no processo sócio-histórico no qual as palavras, expressões e proposições são produzidas (isto é, reproduzidas). (PÊCHEUX, 1988, p. 160, grifo do autor)

Em vista disso, a formação discursiva pode ser entendida "como aquilo que numa formação ideológica 
dada - ou seja, a partir de uma posição dada em uma conjuntura sociohistórica dada - determina o que pode e deve ser dito" (ORLANDI, 2007, p.43), regulando, desse modo, "a referência à interpelação/assujeitamento do indivíduo em sujeito de seu discurso" (BRANDÃO, 2004, p. 49).

Como observa Robin (1977, p. 116), sublinhando a ligação entre a prática discursiva e a formação ideológica, "as ideologias não constituem elementos 'neutros', mas forças sociais das ideologias de classe". E é nesse sentido "que as formações discursivas constituem um componente das formações ideológicas, ou melhor, que as formações ideológicas governam as formações discursivas" (ROBIN, 1977, p. 116). Em outros termos: "não se diz uma coisa qualquer, num momento qualquer, em qualquer lugar". Daí o vínculo estreito com a noção de posicionamento: "as formações discursivas devem ser relacionadas com as posições dos agentes no campo das lutas sociais e ideológicas" (ROBIN, 1977, p. 116, grifos da autora).

Ao passo que o conceito de formação discursiva privilegia o sistema de regras que regula os discursos, a noção de posicionamento, sem deixar de lado todo o peso das injunções históricas, sociais e culturais, focaliza o espaço de um sujeito não totalmente assujeitado, que se (re)configura a cada ato de linguagem, mobilizando estratégias discursivas e realizando escolhas linguísticas, estilísticas e comunicacionais.

Tendo em vista o quadro teórico formulado acima e os propósitos aqui empreendidos, a noção de ethos, no âmbito dessa reflexão, desempenha um papel central, na medida em que ela "permite, de fato, refletir sobre o processo mais geral da adesão dos sujeitos a uma certa posição discursiva" (MAINGUENEAU, 2005, p. 69). O ethos, desde sua formulação na retórica aristotélica, correspondia à "imagem de si que o orador produz em seu discurso, e não de sua pessoa real" (AMOSSY, 2006, p. 220).

Maingueneau (2008, p.53), numa perspectiva discursivo-enunciativa da linguagem, defende uma noção de ethos que considera também "o investimento imaginário do corpo, a adesão 'física' a certo universo de sentido". O autor explica: “As 'ideias' são apresentadas através de uma maneira de dizer que é também uma maneira de ser, associada a representações e normas de disciplina do corpo" (MAINGUENEAU, 2008, p. 53, grifo do autor). Ultrapassando a dimensão verbal, essa concepção de ethos poderia ser pensada a partir de sua remissão àquilo que Maingueneau $(2005$, p. 72$)$ denomina de "figura do fiador", que, por meio de seu tom ${ }^{2}$ e "com base em indícios textuais de diversas ordens", investese "de um caráter e de uma corporalidade, cujo grau de precisão varia conforme os textos". O "caráter" equivale aos traços psicológicos e a "corporalidade" associa-se aos modos de agir (vestir-se, mover-se) na sociedade. A constituição do ethos, para Maingueneau (2008, p. 65), envolve "o conjunto das determinações físicas e psíquicas associadas ao 'fiador' pelas representações coletivas".

Parte constitutiva da cena de enunciação ${ }^{3}$, o ethos, por um lado, é construído discursivamente pelo sujeito, por outro, constitui-se de representações pré-concebidas a partir do ponto de vista do "outro". Assim, assume-se, com Amossy (2006, p. 220), que "o ethos discursivo mantém relação estreita com a imagem prévia que o auditório pode ter do orador ou, pelo menos, com a ideia que este faz do modo como seus alocutários o percebem". O ethos, portanto, está fundamentalmente ligado não somente ao momento interativo em curso, como também ao momento imediatamente anterior à interação. É o que Maingueneau (2005; 2008) chama de ethos pré-discursivo - ou ethos prévio, como preferem Amossy (2005) e Haddad (2005) -; ou seja, a imagem construída antecipadamente ao início do discurso. Ainda para Maingueneau (2008, p. 71), “o ethos de um discurso resulta de uma interação de diversos fatores: ethos pré-discursivo, ethos discursivo (ethos mostrado), mas também de fragmentos do texto em que o enunciador evoca sua própria enunciação (ethos dito)".

Em suma, o ethos é construído na situação interativa em curso, na qual o sujeito realiza escolhas linguísticas em função da imagem que pretende que o "outro" construa sobre ele. É nesse sentido que, no âmbito deste estudo, os conceitos de ethos e de posicionamento identitário são relacionados, visto que ambos configuram modos de enunciação pelos quais os sujeitos assumem determinadas posições discursivas.

Em suma, a identidade é construída e negociada na interação e pressupõe sempre uma interface entre o social/ cultural e o individual, entre o "eu" e o "outro", entre os vários "eus" e entre as diversas vozes que compõem os discursos dos sujeitos. Levando sempre em conta a situação discursiva, a construção do "eu" se dá a partir das imagens que cada um dos participantes fazem de si, do "outro", do tema em questão, e também do espaço e tempo em que se situam. Tudo isso conduz o modo de agir dos sujeitos, refletindo e refratando a própria imagem em construção.

Dito de outro modo, os processos de socialização, os movimentos de subjetivação (que dizem respeito à individualidade do sujeito), os movimentos de objetivação (que implicam a relação do sujeito com o mundo exterior),

\footnotetext{
2 Valendo tanto para a escrita quanto para a oralidade, o termo "tom" é utilizado pelo autor no sentido de que "qualquer discurso escrito, mesmo que a negue, possui uma vocalidade específica, que permite relacioná-lo a uma fonte enunciativa, por meio de um tom que indica quem o disse" (MAINGUENEAU, 2005, p. 72)

3 A "cena de enunciação", postulada por Maingueneau (2005; 2008), admite a possibilidade de construção de diferentes ethé.
} 
os diferentes posicionamentos discursivos assumidos no curso das interações, enfim, todas essas questões balizam uma rede conceitual que se mostra implicada na construção identitária do sujeito em processo de formação acadêmica.

\section{Formação em questão: a constituição identitária profissional}

De imediato, nos textos analisados, a constituição identitária na formação profissional aponta para a necessidade de se considerar os processos de subjetivação e objetivação nela implicada. Trata-se de levar em conta, por um lado, o modo pelo qual o sujeito, ao fazer referência a si, constrói um posicionamento identitário, assumindo determinados papéis no curso da interação; por outro, os processos em que o "eu" é tomado como objeto, o que implica também o reconhecimento de uma subjetividade pessoal, uma vez que a objetividade, como lembra Morin (2005), é, necessariamente, uma operação subjetiva por meio da qual o sujeito reflete sobre sua condição, a partir de um dado lugar social. É o que pode ser observado na seguinte passagem, extraída de um relatório do 2 o período:

\begin{abstract}
O projeto de pesquisa proposto e orientado pelos professores M. e I., foi uma das tarefas mais difíceis durante o período. Particularmente, achei o tema escolhido um pouco complexo, por não haver "textos escritos", e sendo assim, tivemos que analisar as imagens. Porém no final, não só na apresentação do meu grupo como na dos outros grupos também, percebi a evolução para desenvolver esse tipo de atividade (L1-2P). ${ }^{4}$
\end{abstract}

No trecho acima, o sujeito ressalta a dificuldade da tarefa: "foi uma das tarefas mais difíceis durante o período". Em seguida, registra sua opinião, relativizando a dificuldade do trabalho proposto pelos professores: "Particularmente, achei o tema escolhido um pouco complexo". No mesmo enunciado, por meio da primeira pessoa do plural, as vozes do grupo são trazidas à cena: "tivemos que analisar as imagens". Por fim, o aluno, posicionando-se enquanto tal, - aquele que está a construir um saber, a vivenciar as práticas acadêmicas, a inserir-se nelas como um sujeito em processo de aprendizagem - elogia não apenas o próprio grupo de trabalho, mas a turma, em sua totalidade, e, ao fazê-lo, acaba por realçar, na evolução da turma, sua própria percepção do fenômeno e, mais que isso, a sua inserção nesse domínio de práticas do fazer acadêmico: "não só na apresentação do meu

\footnotetext{
4 Para a identificação dos textos, é utilizada a letra inicial do nome do aluno seguida de números, e para identificar os períodos do Curso, são utilizadas as siglas $2 \mathrm{P}$ ( $2^{\circ}$ período $)$ e $7 \mathrm{P}$ ( $7^{\circ}$ período $)$.
}

grupo como na dos outros grupos também, percebi a evolução para desenvolver esse tipo de atividade".

A seu turno, lado a lado com a inserção do sujeito na coletividade da sala, a primeira pessoa do plural, em alguns casos, parece funcionar menos como um atenuador do mérito individual, do que como uma estratégia em que o aluno incorpora ao seu discurso a voz do interlocutor/ leitor. Observe-se, no excerto abaixo, que as referências à pessoa apresentam-se fundamentalmente como um elemento de articulação do gerenciamento de vozes:

\begin{abstract}
Podemos visualizar temas como sociedade e leitura, no segundo período; começarei por leitura e, para isso, daremos um salto para o início do semestre, e, adentraremos a aula da J.; (ufa! gênio forte, mas dona de uma eloquência apaixonante), e nos deparamos com uma aula de produção de texto muito diferente das convencionais, mas superinteressante [...] (M1-2P).
\end{abstract}

Ao que se nota, a recorrência de verbos na primeira pessoal do plural ("podemos"; "daremos"; "adentraremos"; "deparamos"), evidenciam uma atitude do sujeito de incluir-se no grupo, colocando-se, assim, em posição de similitude/simetria em relação a ele (convergência de vozes). Ao mesmo tempo, notam-se movimentos de divergência, nos quais o sujeito, ao priorizar a própria opinião, exclui-se do grupo e individualiza-se, construindo, nesse movimento, uma imagem positiva de si.

Nesse caso, a remissão às pessoas do discurso sugere que o posicionamento identitário assumido postula uma relação dialógica, trazendo à cena enunciadores e enunciatários envolvidos na interação, ao recorrer ao "nós" (e às formas verbais selecionadas que intentam monitorar o "outro" na cena) e ao recorrer ao "eu" (a forma verbal sinaliza quem orquestra a cena). A alternância entre o "eu" e o "nós" é frequente nos textos analisados e parece ser uma estratégia persuasiva em que o sujeito orienta seu dizer a fim de passar uma imagem de si centrada no bom aprendizado, pensada para interpelar e/ou monitorar seu enunciatário.

Um processo relativamente semelhante ocorre no excerto abaixo, extraído de um relatório de intervenção didática do $7^{\circ}$ período:

\footnotetext{
Posso dizer que, no geral, a atividade foi bem recebida $e$ aceita pelos alunos, que se comprometeram e participaram ativamente, levando questões acerca do texto, discutindo o material, e, por fim, realizando a atividade proposta. Claro que alguns alunos mostraram-se alheios e dispersos, preferindo conversar a realmente participar da aula, mas, considerando-se o grupo como um todo, acredito que a aula tenha sido bem-sucedida e que a intervenção tenha atingido seus objetivos (D1-7P).
} 
Aqui, contudo, a objetivação do sujeito mostra-se sob novos ângulos. Ao falar, respectivamente, da atividade "bem recebida", da aula "bem-sucedida" e da intervenção que atingiu seus objetivos, o sujeito conjuga, nessa cena, as posições tanto de aluno como de professor, objetivando, com isso, as imagens de si ali construídas, sob o enquadre da atividade em questão (relatório de estágio). Apreende-se o movimento de objetivação, tendo em vista as modalizações de que se vale o aluno-professor para: a) expressar e generalizar a aceitação da atividade pelos alunos: "posso dizer que, no geral [...]"; b) apresentar, sob a forma de evidência, o alheamento e a dispersão de alguns alunos como um fato natural na interação com a turma no campo de estágio: "claro que alguns alunos mostraramse alheios e dispersos"; e c) retornar à generalização dos bons resultados da intervenção: "mas, considerando-se o grupo como um todo, acredito que [...]".

Como é possível notar, seja pela abordagem da própria atuação profissional, (como no caso do aluno do $7^{\mathfrak{0}}$ período), seja pela abordagem das atividades realizadas ao longo do semestre, (como no caso do aluno do $2^{\text {Q }}$ período), as imagens do "eu" são construídas por meio de referências a si e ao "outro". Os processos de subjetivação e objetivação, assim, apresentam-se diretamente vinculados à construção identitária do profissional em formação aqui analisado.

\subsection{0 saber-fazer em múltiplas vozes}

Nos textos em exame, o gerenciamento de vozes apresenta-se vinculado às estratégias linguísticodiscursivas mobilizadas pelos sujeitos na tentativa de construir imagens positivas de si. Esse vínculo, de certo modo, está inscrito no próprio evento comunicativo em questão, afinal, os relatórios preveem uma descrição das experiências dos alunos - experiências acadêmicas, no caso do $2^{\mathrm{o}}$ período, e experiências docentes, no caso do $7^{\circ}$ período. Portanto, o saber-fazer em múltiplas vozes é constitutivo dos relatos analisados. Essas vozes originamse de diferentes lugares: do discurso teórico-acadêmico, do discurso prático-pedagógico, bem como da própria história pessoal vivida pelos alunos.

Outro procedimento comum nos textos analisados refere-se à remissão às vozes dos autores estudados no decorrer do Curso, isto é, às vozes de "autoridade", que embasam o que é dito nos relatos. O discurso relatado, nesses casos, funciona como uma forma de demonstrar que a aprendizagem dos conceitos trabalhados foi bem-sucedida e, desse ponto de vista, contribui para a compreensão dos modos pelos quais, no âmbito da prática acadêmica, o gerenciamento de vozes articulase à imagem dos enunciadores e à construção de uma identidade profissional:
Mikhail Bakhtin em seu texto "a interação verbal" 1981, define que "a enunciação é o produto da interação de dois indivíduos socialmente organizados e, mesmo que não haja um interlocutor real este pode ser substituído pelo representante médio do grupo social ao qual pertence o locutor". Essa afirmação completa de forma perfeita, a teoria de enunciação de Benveniste pois através dela, percebemos a relação da linguagem com o poder (sociedade) (B1-2P).

No estudo da subjetividade na linguagem, Benveniste (1991, p. 85) questiona e critica essa noção de linguagem dizendo que "Falar de instrumento, é pôr em oposição o homem e a natureza", mostrando que não se pode mais conceber a linguagem e o individuo dessa forma porque "não atingimos nunca o homem separado da linguagem e não o vemos nunca a inventando" (F1-2P).

Nos casos acima, o discurso relatado traz as marcas da prática acadêmico-científica, como mostram os verbos empregados para introduzir as vozes dos autores citados: "define"; "questiona e critica". Essas expressões verbais podem ser vistas como pistas que evocam o modo como os alunos apreendem a voz dos autores citados, isto é, assinalam a leitura/compreensão que deles têm, pautada por uma posição crítica e dialógica, na medida em que refletem sobre o papel dos textos/autores lidos relativamente às suas formações teóricas, aos objetos de estudo que compõem o plano de trabalho do período em curso e às relações de diálogo entre os autores citados. Em suma, nos excertos em exame, o gerenciamento de vozes é uma ação discursiva e dialógica por meio da qual se pode apreender o modo como o aluno se constrói em termos de sua formação acadêmica, deixando assim refletir um dado posicionamento identitário na cena em questão.

No próximo exemplo, por sua vez, a tentativa de se reportar ao discurso do "outro" é articulada à tentativa de se posicionar diante daquilo que se diz:

[a professora] Passava a matéria de forma tradicional e dizia que esse era o único jeito de os alunos realmente aprenderem, que com os outros métodos, por exemplo, investindo mais na produção de textos, eles não aprendiam e demorava mais (A2-7P).

O jogo de vozes presente nesse relato está estruturado em dois planos básicos: no primeiro deles, o aluno reporta-se ao discurso da professora observada em campo de estágio; no segundo, traz à cena todo um debate entre a didática tradicional e as novas concepções de ensino/ aprendizagem que, como se sabe, são privilegiadas pelo Curso de Letras e pelos documentos orientadores da prática educacional, tal como os Parâmetros Curriculares Nacionais (PCN's), por exemplo. 


\subsection{A subjetividade em cena}

Os modos pelos quais o sujeito, ao fazer referência a si, constrói um posicionamento identitário, vinculam-se às estratégias discursivas mobilizadas em função da cena enunciativa em que os textos foram produzidos, assim como o gerenciamento de vozes vincula-se às estratégias mobilizadas pelos sujeitos na tentativa de construir imagens positivas de si. Cumpre agora refletir sobre como os mecanismos enunciativos atuam nesse processo em que se adensa o problema da subjetividade na formação profissional. Para isso, pode-se partir dos excertos abaixo, focalizando as estratégias de referência pessoal:

Concluo este relatório agradecendo mais uma vez a todos os meus colegas que me ajudaram nessa caminhada e dizer para todos os professores sem exceção que aprendi muito nestes dois períodos e que sentirei saudades das "discussões" feitas neste tempo em que, além de construir a minha subjetividade através da linguagem, consegui me situar dentro do meu "meio social" (B1-2P).

As análises textuais contribuíram muito para o meu aprendizado de texto, discurso e enunciação, pois através delas consegui compreender melhor as cenas enunciativas, os efeitos de sentido (F1-2P).

Como estamos tratando de uma intervenção pedagógica, com prazo para ser cumprida, considerando o planejamento de aulas do professor da escola, não poderia dispor da quantidade de aulas necessárias para realizar a seqüência didática completa, assim, optei por adaptá-la as condições que dispunha, sem deixar de lado o objetivo central e sem prejudicar os alunos (D1-7P).

Quanto ao tema da produção, ela [a professora observada] deixou em aberto. Assim, a estagiária queria trabalhar com algo que iria acrescentar algum conhecimento. Lendo o artigo da revista Nova Escola de fevereiro, a estagiária pensou em trabalhar com os gêneros resumitivos: sinopse, resumo e resenha (F2-7P).

Nos dois primeiros excertos, o aprendizado acadêmico é abordado sob um ponto de vista predominantemente individual, como, de imediato, demonstram as marcas de primeira pessoa indicadas por pronomes e desinências verbais ("concluo"; "meus"; "me"; "aprendi"; "sentirei"; "minha"; "consegui"). Tais excertos, de fato, trazem à cena elementos exteriores aos quais se atribui um papel relevante no aprendizado, mas, ainda assim, a ênfase recai sobre a individualidade, como se nota em passagens como: "os meus colegas [...] me ajudaram nessa caminhada"; "as análises textuais contribuíram para o meu aprendizado".

No primeiro exemplo, a "conclusão" do aluno vai do agradecimento à afirmação do bom aprendizado. Fazendo referência aos conceitos discutidos por Benveniste e por
Bakhtin, respectivamente, o aluno afirma que, "além de construir a minha subjetividade através da linguagem, consegui me situar dentro do meu "meio social"" Destaque-se que, mais importante que explicitar a construção de uma subjetividade, é o fato de que essa própria explicitação metaenunciativa é um recurso por meio do qual o sujeito busca se apresentar enquanto bom aluno, recorrendo a um jogo de vozes ao aludir ao quadro teórico dos dois primeiros períodos do Curso. De modo semelhante, no segundo trecho, o sujeito também focaliza o bom aprendizado, recorrendo, para isso, a termos e conceitos estudados no decorrer do semestre: "análises textuais", "texto", "discurso", "enunciação", "cenas enunciativas", "efeitos de sentido".

Já nos dois últimos excertos, extraídos de relatos de alunos do $7^{\circ}$ período, o enfoque recai na aplicação da aprendizagem do fazer docente. Diferentemente do que ocorre nos exemplos anteriores, em que são recorrentes verbos e expressões relativos ao campo semântico do "aprendizado teórico", aqui, a ênfase maior é dada a verbos que indicam as escolhas/decisões dos sujeitos do ponto de vista do "aprendizado da prática", como é o caso de "optei" (em D1) e "pensou" (em F2), verbos que, no contexto dos relatos, apontam para a autonomia dos sujeitos frente ao desenvolvimento do trabalho no campo de estágio. Desse modo, primeiramente, D1 justifica o fato de ter optado por adaptar sua sequência didática às condições de que dispunha: "Como estamos tratando de uma intervenção pedagógica, com prazo para ser cumprida, considerando o planejamento de aulas do professor da escola [...]". Em seguida, o aluno-professor relata sua preocupação em não "deixar de lado o objetivo central" e em "não prejudicar os alunos", com o intuito de apresentar suas habilidades em adequar-se às situações com que se deparava, buscando, assim, demonstrar sua autonomia em tomar decisões e, por conseguinte, sua formação acadêmico-profissional bem-sucedida.

Como se vê, o posicionamento identitário dos sujeitos pode ser apreendido por meio das relações de interlocução estabelecidas entre os autores estudados no decorrer do semestre e os autores com os quais estes dialogam; entre os professores do período e as teorias estudadas; e também entre os alunos e seus potenciais interlocutores.

\section{Considerações finais}

Este estudo buscou analisar os posicionamentos identitários no processo de formação profissional em Letras a partir de três direções distintas, mas interdependentes. Sendo assim, se as imagens de si, o jogo de vozes e os mecanismos enunciativo-discursivos permitem, cada qual a seu modo, no fluxo do funcionamento da cena 
enunciativa, a observação de formas particulares pelas quais os sujeitos se posicionam em seu discurso, acredita-se que, para uma investigação mais abrangente do vínculo entre esses posicionamentos e o processo de formação acadêmico-profissional, é necessário tomá-los em conjunto, atentando, sobretudo, para as articulações que estabelecem entre si. Foi o que este trabalho se propôs a fazer.

Levando em consideração as especificidades do corpus de análise, relativamente a suas condições de produção, circulação e recepção, o presente estudo teve em vista demonstrar que: a) diferentes identidades são construídas por meio das relações que o sujeito mantém com o "outro" e com os "outros eus" que o constituem; b) as identidades que emergem desse processo são agenciadas discursivamente com base nas posições enunciativas assumidas pelos participantes da interação; c) as identidades são negociadas socialmente em função da situação e dos diferentes papéis de que se investe o sujeito nas diferentes práticas de linguagem de que participa; d) as posições identitárias agenciadas pelo sujeito dão-se em função de um determinado projeto de dizer; e) as imagens de si, reflexas do jogo interlocutivo que o sujeito projeta no texto, são construídas e negociadas discursivamente, em estreita relação com as imagens de si que pretende que o "outro" construa sobre ele; f) o ethos, atualizado pelo sujeito em suas produções escritas, está diretamente implicado tanto com as intenções subjacentes às atividades que engendram os relatos, quanto com as expectativas dos professores do período e do próprio Projeto Pedagógico do Curso de Letras; e, por fim, g) os mecanismos enunciativos - particularmente, o jogo de vozes, as estratégias de referência pessoal e as modalizações - são pistas deixadas pelo sujeito em seu discurso capazes de revelar ao analista do discurso os modos pelos quais os sujeitos manifestam enunciativa $\mathrm{e}$ discursivamente suas posições identitárias na configuração de seus textos, destacando, assim, as imagens que constroem sobre a própria formação, os papéis sociais que assumem e suas ações na esfera acadêmica.

À luz desse quadro, a abordagem transversal do percurso de formação dos sujeitos pesquisados permitiu observar diferenças significativas de posicionamentos identitários e, por conseguinte, diferenças não menos significativas nas manifestações dos mecanismos enunciativos mobilizados nas produções textuais. Como demonstram as análises empreendidas por este estudo, boa parte dessas diferenças pode, de fato, ser imputada à própria natureza da atividade - a produção de um relatório acadêmico -, como também à etapa de formação acadêmico-profissional do estudante. Desse modo, conforme se verificou, aos alunos do $2^{\mathrm{O}}$ período, iniciantes no meio acadêmico, é dada a tarefa de relatar e refletir sobre suas experiências do ponto de vista teóricoconceitual, assinalando a aprendizagem construída no decurso do período dos objetos de conhecimento, isto é, dos conteúdos trabalhados no decorrer do semestre letivo. Aos alunos do $7^{\circ}$ período, por sua vez, cumpre relatar e refletir sobre suas experiências pedagógicas do ponto de vista da prática docente, destacando não apenas o aprendizado dos conteúdos até então trabalhados no Curso, mas, sobretudo, a capacitação para a docência, caso em que as posições de aluno e professor encontram-se imbricadas e sobrepostas.

Quanto às manifestações dos mecanismos de enunciação, as análises dos dados mostram ainda outras diferenças determinantes para a compreensão dos posicionamentos identitários dos sujeitos pesquisados. A observação de aspectos relacionados ao jogo de vozes, por exemplo, demonstra que os alunos do $2^{\mathrm{o}}$ período, devido à experiência acadêmica ainda incipiente, em processo de construção, tendem a sofrer maior influência de uma tradição escolar voltada para o "conteúdo informacional" daquilo que foi trabalhado e/ou aprendido no semestre do que para as diversas estratégias de discurso reportado, o que, por sua vez, incide sobre uma plena responsabilidade enunciativa do que é dito. Ainda, a observação das estratégias de referência pessoal e das modalizações demonstra que os alunos do $2^{\circ}$ período tendem também a explicitar, com bastante recorrência, marcas de subjetividade e de interatividade, ao contrário do que, em geral, pôde-se observar nos relatórios de alunos do $7^{\circ}$ período, nos quais as marcas linguísticas de subjetividade, não raro, são suprimidas, indicando uma tentativa de adequação a restrições tradicionalmente impostas pela prática textual acadêmico-científica, ou seja, realça-se o fato em discussão - experiência do estágio de docência -, apagando, em larga medida, uma posição enunciativa, o que, vale lembrar, não se neutraliza a emergência de um posicionamento identitário.

A esse respeito, a análise dos dados demonstrou que o sujeito não se manifesta somente por meio de referências linguísticas, tampouco somente pelas marcas modais que indiciam sua presença, mesmo quando as referências linguísticas são suprimidas: o sujeito manifesta-se no jogo de vozes e, principalmente, no agenciamento das posições que assume em seu discurso. E, mesmo que o foco da análise esteja na constituição identitária do sujeito por meio do seu discurso, não se pode desconsiderar que se trata de um sujeito que preexiste e, ao mesmo tempo, se constitui em sua ação de linguagem; um sujeito que possui um corpo, uma história e uma trajetória social e cultural que o determinam tanto quanto o particularizam; um sujeito cujas relações interpessoais são decisivas para suas tomadas de posições identitárias/ideológicas/subjetivas. Seu discurso é, assim, atravessado por 
múltiplas vozes, mas nem por isso desprovido de traços de sua individualidade; sua identidade é multifacetada e heterogênea e, por isso, um processo em contínua (trans)formação.

Em suma, os resultados a que chegou este estudo permitem assinalar que o sujeito não está no "dito", mas nos "modos de dizer", instância da gestão do texto e, portanto, da atualização do discurso em que se flagram os posicionamentos identitários.

\section{Referências}

ALTHUSSER, Louis. Aparelhos ideológicos de Estado: notas sobre os aparelhos ideológicos de Estado. Rio de Janeiro: Graal, 1983.

AMOSSY, Ruth. O ethos na intersecção das disciplinas: retórica, pragmática, sociologia dos campos. In: AMOSSY, Ruth (Org.). Imagens de si no discurso: a construção do ethos. São Paulo: Contexto, 2005. p. 119-144.

AMOSSY, Ruth. Ethos. In: CHARAUDEAU, Patrick; MAINGUENEAU, Dominique. Dicionário de Análise do Discurso. Tradução de Fabiana Komesu et al. 2. ed. São Paulo: Contexto, 2006. p. 220-234.

BAKHTIN, Mikhail. Os gêneros do discurso. In: Estética da criação verbal. Tradução de Paulo Bezerra. 4.ed. São Paulo: Martins Fontes, 2003. p. 261-335.

BAKHTIN, Mikhail; VOLOCHINOV, Valentin Nikolaevich. Marxismo e filosofia da linguagem: problemas fundamentais do método sociológico na ciência da linguagem. Tradução Michel Lahud e Yara Frateschi Vieira. 11. ed. São Paulo: Hucitec, 2004.

BENVENISTE, Émile. Problemas de linguística geral I. Tradução Maria da Glória Novak e Maria Luisa Neri. 4.ed. Campinas: Pontes, 1995.

BEZERRA, Paulo. Polifonia. In: BRAIT, Beth (Org.). Bakhtin: conceitos-chave. São Paulo: Contexto, 2007. p. 191-200.

BRANDÃO, Helena. Introdução à análise do discurso. 2. ed. Campinas, SP: Editora da UNICAMP, 2004.

BRONCKART, Jean-Paul. Atividade de linguagem, textos e discursos: por um interacionismo sociodiscursivo. Tradução Anna Rachel Machado, Péricles Cunha. São Paulo: EDUC, 2003.

BRONCKART, Jean-Paul. O agir nos discursos: das concepções teóricas às concepções dos trabalhadores. Tradução Anna Rachel Machado e Maria de Lourdes Meirelles Matencio. Campinas, SP: Mercado de Letras, 2008.

DUCROT, Oswald. O dizer e o dito. Campinas, SP: Pontes, 1987.

FOUCAULT, Michel. A arqueologia do saber. Tradução Luiz Felipe Baeta Neves. Rio de Janeiro: Forense Universitária, 2007.

GNERRE, Maurizzio. Linguagem, escrita e poder. São Paulo: Martins Fontes, 1988.

HADDAD, Galit. Ethos prévio e ethos discursivo: o exemplo de Romain Rolland. In: AMOSSY, Ruth (Org.). Imagens de si no discurso: a construção do ethos. São Paulo: Contexto, 2005. p. 119-144.
HALL, Stuart. Quem precisa da identidade? In: WOODWARD, Kathryn; SILVA, Tomaz Tadeu da; HALL, Stuart (Org.). Identidade e diferença: a perspectiva dos estudos culturais. Petrópolis, RJ: Vozes, 2000. p. 103-131.

HALL, Stuart. A identidade cultural na pós-modernidade. Tradução Tomaz Tadeu da Silva, Guaracira Lopes Louro. Rio de Janeiro: DP\&A, 2005.

HOLLAND, Dorothy et al. Identity and agency in cultural worlds. Cambridge: Harvard University Press, 1998.

HORTON, Paul B.; HORTON, Robert H. Introdução à sociologia. São Paulo: Brasiliense, 1975.

KLEIMAN, Angela B. (Org.). Os significados do letramento: uma nova perspectiva sobre a prática social da escrita. Campinas: Mercado de Letras, 1995.

KLEIMAN, Angela B. A construção de identidades em sala de aula: um enfoque interacional. In: SIGNORINI, Inês (Org.). Lingua(gem) e identidade: elementos para uma discussão no campo aplicado. Campinas, SP: Mercado de Letras; São Paulo: Fapesp, 1998. p. 267-302.

KLEIMAN, Angela B.; MATENCIO, Maria de Lourdes Meirelles (Org.). Letramento e formação do professor: práticas discursivas, representações e construção do saber. Campinas, SP: Mercado de Letras, 2005.

$\mathrm{KOCH}$, Ingedore G. Villaça. Introdução à linguística textual: trajetórias e grandes temas. São Paulo: Martins Fontes, 2004a.

KOCH, Ingedore G. Villaça. Argumentação e linguagem. São Paulo: Cortez, 2004b.

KOCH, Ingedore G. Villaça. Referenciação e orientação argumentativa. In: KOCH, Ingedore G. Villaça; MORATO, Edwiges Maria; BENTES, Anna Christina (Org.). Referenciação e discurso. São Paulo: Contexto, 2005. p.33-52.

MAINGUENEAU, Dominique. Ethos, cenografia, incorporação. In: AMOSSY, Ruth (Org.). Imagens de si no discurso: a construção do ethos. São Paulo: Contexto, 2005. p. 69-92.

MAINGUENEAU, Dominique. Posicionamento. In: CHARAUDEAU, Patrick; MAINGUENEAU, Dominique. Dicionário de Análise do Discurso. Tradução Fabiana Komesu et al. 2. ed. São Paulo: Contexto, 2006. p. 160-163.

MAINGUENEAU, Dominique. Problemas de ethos. In: Cenas da enunciação. Organização de Sírio Possenti e Maria Cecília Pérez de Souza e Silva. São Paulo: Parábola, 2008. p. 55-73.

MARCUSCHI, Luiz Antônio. Da fala para a escrita: atividades de retextualização. 2. ed. São Paulo: Cortez, 2003.

MATENCIO, M. L. M. Estudo da língua falada e aula de língua materna: uma abordagem processual da interação professor/ alunos. Campinas: Mercado de Letras, 2001.

MORIN, Edgar. A noção de sujeito. In: SCHNITMAN, D. (Org.). Novos paradigmas, cultura e subjetividade. Porto Alegre: ARTMED, 1996.

MORIN, Edgar. A cabeça bem-feita: repensar a reforma, reformar o pensamento. Tradução Eloá Jacobina. 5. ed. Rio de Janeiro: Bertrand Brasil, 2001.

MORIN, Edgar. O método 5: a humanidade da humanidade. Tradução Juremir Machado da Silva. 3. ed. Porto Alegre: Sulina, 2005 . 
ORLANDI, Eni. Análise de discurso: princípios e procedimentos. Campinas, SP: Pontes, 2007.

PÊCHEUX, Michel. A forma-sujeito do discurso. In: Semântica e discurso: uma crítica à afirmação do óbvio. Tradução Eni Pulcinelli Orlandi et al. Campinas: Editora da UNICAMP, 1988. p. 159-185.

PUC MINAS. Projeto Pedagógico do Curso de Letras (Betim, Coração Eucarístico e São Gabriel). Belo Horizonte, Novembro de 2005.

ROBIN, Règine. Formação social, prática discursiva e ideologia. In: História e Linguística. São Paulo: Cultrix, 1977. p. 88-134.

SIGNORINI, Inês. Língua(gem) e identidade: elementos para uma discussão no campo aplicado. Campinas, SP: Mercado de Letras; São Paulo: Fapesp, 1998.
SILVA, Jane Quintiliano G.; MATENCIO, Maria de Lourdes Meirelles. Referência pessoal e jogo interlocutivo: efeitos identitários. In: KLEIMAN, Angela B.; MATENCIO, Maria de Lourdes Meirelles (Org.). Letramento e formação do professor: práticas discursivas, representações e construção do saber. Campinas, SP: Mercado de Letras, 2005. p. 245-266.

SOARES. Magda. Letramento: um tema em três gêneros. 2. ed. Belo Horizonte: Autêntica, 2003.

WOODWARD, Kathryn. Identidade e diferença: uma introdução teórica e conceitual. In: WOODWARD, Kathryn; SILVA, Tomaz Tadeu da; HALL, Stuart (Org.). Identidade e diferença: a perspectiva dos estudos culturais. Petrópolis, RJ: Vozes, 2000. p. 7-72.

Recebido: 16 de maio de 2013

Aprovado: 22 de agosto de 2013

Contato: renatamarquesgomide@gmail.com 